\title{
Ultrasonographic Discrimination of Benign and Malignant Breast Lumps with Histopathological Correlation
}

\author{
Tarana Yasmin ${ }^{1}$, Sohely Sultana ${ }^{2}$, Mashah Binte Amin ${ }^{3}$, Syed Shamsul Arephen ${ }^{4}$, \\ Sania Rafat ${ }^{5}$, Tayseer Farzana ${ }^{6}$ \\ Received: October 29, 2014 Accepted: June 13, 2015 \\ doi: http://dx.doi.org/10.3329/jemc.v5i3.24746
}

\begin{abstract}
Background: A lump in the breast is a cause of great concern. High frequency high resolution ultrasonogram helps in its evaluation. With major advances in ultrasonographic technology during the past 20 years, ultrasonogram can now distinguish benign and malignant solid breast lumps. Knowledge of the specific benign and malignant ultrasonographic characteristics of breast lumps is imperative for accurate diagnosis and optimal patient management. Objective: To determine the validity of ultrasound in the assessment of palpable breast lump by detecting the sensitivity, specificity, accuracy, positive predictive value and negative predictive value of ultrasonogram in distinguishing benign and malignant breast lumps. Materials and Methods: This cross sectional study was done in the department of Radiology and Imaging of Bangabandhu Sheikh Mujib Medical University (BSMMU), Dhaka in collaboration with the department of Pathology of BSMMU for histopathological correlation during July 2008 to June 2009. A total of 100 patients who were clinically suspected of having breast lump were included in this study. Data on clinical presentation, ultrasonographic findings including histopathological reports were collected and documented in structured forms. Analysis was done using SPSS 13.0 version. Results: The study was done in 100 women of 18-70 years of age with mean age $41.46 \pm 11.62$ years. Breast lumps were found with associated clinical presentation of pain in $26(26 \%)$ cases, discharge in $12(12 \%)$ cases, skin changes in $28(28 \%)$ cases, nipple retraction in $10(10 \%)$ cases, and palpable lymph nodes in $10(10 \%)$ cases. On ultrasonogram, lesions were diagnosed as benign in $62 \%$ cases and malignant in 38\% cases. Out of sonographically diagnosed 62 benign lesions 58 (93.5\%) were also proved benign histopathologically and $4(6.5 \%)$ as malignant. Out of 38 sonographically malignant lesions, 34 (89.5\%) were also proved as malignant histopathologically and 4 (10.5\%) as benign. Conclusion: Ultrasonographic findings of benign and malignant breast lumps correlated well in most of the cases with the histopathological results. Therefore, it can be concluded that ultrasonogram is a useful imaging tool to discriminate benign and malignant breast lumps and thus we can reduce unnecessary breast biopsies, patient discomfort and anxiety in addition to increase in cost of the patient.
\end{abstract}

Key words: Benign; Malignant; Palpable breast lumps; Ultrasonogram

J Enam Med Col 2015; 5(3): 151-156

\section{Introduction}

Breast lump is the localized swelling, protuberance or mass in the breast. A lump may be a cyst, inflammatory mass, a benign or a malignant tumor. Palpable breast

masses are common and very frequently benign. The most common breast lumps are fibroadenoma in young women, cyst or fibrocystic changes in middle-aged

1. Assistant Professor, Department of Radiology \& Imaging, Enam Medical College \& Hospital, Savar, Dhaka

2. Former Specialist, Department of Radiology \& Imaging, United Hospital Ltd., Dhaka

3. Assistant Professor, Department of Radiology \& Imaging, Enam Medical College \& Hospital, Savar, Dhaka

4. Consultant, Department of Radiology \& Imaging, Enam Medical College \& Hospital, Savar, Dhaka

5. Former Junior Consultant, Department of Radiology \& Imaging, Delta Medical College \& Hospital, Dhaka

6. Consultant Radiologist, Popular Diagnostic Center, Dhaka

Correspondence Tarana Yasmin, Email: tarana_hassan@hotmail.com 
women and cancer in older women. ${ }^{1}$ Breast cancer is one of the most common cancers in women, accounting for $21 \%$ of cancers diagnosed ${ }^{2}$ and second most common cause of cancer-related mortality. The incidence of breast cancer is rising all over the world. Since breast cancer prevention is still theoretical, efforts have focused on early detection. Breast cancer is more easily treated and often curable if it is diagnosed early. But noninvasive diagnosis of breast cancer remains a major clinical problem. The distinction by physical examination of physiological nodularity from abnormal masses can be difficult. The clinical differentiation of a malignant mass from a benign one is difficult and consequences of missing a palpable carcinoma are high.

Recent research on service screening programs suggests that participation in modern, organized service screening may reduce the risk of breast cancer by $40 \%$ or more. ${ }^{3}$ It means that early and sensitive diagnosis represents a better prognosis.

There are many imaging modalities for detecting breast lumps. But mammography and sonography are currently the most sensitive modalities. For early detection of breast cancer, mammography is currently the most widely used screening modality, but it has a low negative predictive value. In patients with palpable abnormalities of the breast, false-negative rate for mammography has been reported to be as high as $18 \%$. $^{4}$ Therefore, many masses referred for breast biopsy on the basis of mammography findings are actually benign.

Because of the higher false-negative rate of mammography, biopsy is still performed for clinically questionable palpable abnormalities. The false-negative rate of mammography for breast cancer between $10-15 \%$ is generally accepted. ${ }^{5}$ As clinical breast examination is not absolute, many surgeons liberally performed fine-needle aspiration, core biopsies, open surgical biopsies. But by biopsies we find cancer in only $10 \%$ to $30 \%$ cases. $^{6}$ This means that $70 \%$ to $90 \%$ of breast biopsies are performed for benign diseases which induce unnecessary patient discomfort and anxiety in addition to increase in cost to the patient. So, there is a great need for development of additional reliable methods to complement the existing diagnostic procedures to avoid unnecessary biopsy. The initial screening studies ${ }^{7,8}$ with sonography in the 1980 s were not as successful as the present study. A decade later favorable results for sonography of palpable breast masses were also noted in more studies. ${ }^{9,10}$ So the purpose of our study is to establish the diagnostic usefulness of ultrasonogram in differentiating benign and malignant breast lumps by evaluating the ultrasonographic findings of benign and malignant breast lumps, comparing the ultrasonographic findings, correlating the ultrasonographic findings with histopathological findings and thus to determine and validate the diagnostic accuracy, sensitivity and specificity of ultrasonogram in differentiating benign and malignant breast lumps.

\section{Materials and Methods}

This cross sectional study was carried out in the department of Radiology \& Imaging of Bangabandhu Sheikh Mujib Medical University (BSMMU), Dhaka in collaboration with the department of Pathology of BSMMU for histopathological correlation during July 2008 to June 2009. This study was carried out on consecutively selected 100 patients ranging from 18-70 years having breast lumps and supported by ultrasonogram.

Ultrasonography was performed with high frequency $(7.5 \mathrm{MHz})$ linear array transducer. Supine oblique or supine position was recommended to reduce breast thickness and to improve visualization of deeper tissues. One or both arms were elevated behind the head or neck to stretch the pectoralis muscles for better fixation and immobilization of the breast. Scanning was done perpendicular to the skin surface. Finally ultrasonographic diagnoses of breast lumps were correlated with histopathological reports.

\section{Following outcome variables were observed}

Demographic and clinical variables: Age of the patient. Clinical features-Lump in the breast, pain, discharge, skin change, distortion of nipple, palpable lymph node.

Imaging variables: Size of mass, site of lesion, type of lesion (solid/cystic), shape, echogenicity, margin, pseudocapsule, axial orientation, edge shadows, posterior acoustic phenomena, compressibility and mobility, architectural disruption.

Relevant data of all the patients were recorded in a predesigned structured data sheet. Then all data were checked, edited and analyzed with the help of SPSS (statistical package for social sciences) 13.0 version. For the validity of the study outcome sensitivity, specificity, accuracy, positive and negative predictive values were calculated out after confirmation of the diagnosis histopathalogically.

\section{Results}

In this study, mean age of the patients was $41.46 \pm$ 11.62 years ranging from 18-70 years. Along with presentation with the complaint of lump in the breast, $26 \%$ cases complained of pain, $12 \%$ presented with discharge, $28 \%$ presented with skin changes, $10 \%$ cases with nipple retraction and $10 \%$ presented with palpable axillary lymph nodes. 
On examination of the breast lump, skin thickening was found in $22 \%$ cases, in $10 \%$ cases lump was discrete and in $62 \%$ cases were single. In $16 \%$ cases lump was hard, $62 \%$ cases rubbery, $18 \%$ soft and $18 \%$ cases were painful.

Sonographically diagnosed benign lumps had the following criteria - oval and round shaped in $62 \%$ cases, well-circumscribed smooth narrow margin in $52 \%$ cases, narrow but jagged border having $<3$ lobulations in $10 \%$ cases, width/AP ratio $>1.4$ in $62 \%$ cases, anechoic in $8 \%$ cases, hypoechoic in $14 \%$ cases, hyperechoic in relation to fat in $40 \%$ cases, $48 \%$ cases were homogeneous and $14 \%$ cases were intermediate in echotexture, narrow bilateral edge shadow in $52 \%$ cases but absent edge shadow in $10 \%$ cases, posterior acoustic enhancement in $46 \%$ cases but $16 \%$ cases were unremarkable, thin echogenic pseudocapsule were seen in $62 \%$ cases, $28 \%$ cases compressible and $34 \%$ cases were less compressible, $62 \%$ cases were mobile and showed no architectural disruption.

Sonographically lumps were diagnosed as malignant having following criteria - irregular shape with ill defined margin in $38 \%$ cases, width/AP ratio $<1.4$ in $38 \%$ cases, $38 \%$ cases were heterogeneous and more hypoechoic, broad unilateral edge shadow was seen in $8 \%$ cases and no edge shadow was found in $30 \%$ cases, posterior acoustic attenuation was in 34\% cases and $4 \%$ cases were unremarkable, $34 \%$ cases were uncapsulated and $4 \%$ cases had thick echogenic halo, $38 \%$ cases were noncompressible, fixed and showed architectural distortion (Table I).

Table I: Distribution of the respondents by ultrasonographic findings $(\mathrm{N}=100)$

\begin{tabular}{|c|c|c|c|}
\hline USG findings & USG diagnosis & Frequency & Percentage \\
\hline \multicolumn{4}{|l|}{ Shape } \\
\hline $\begin{array}{l}\text { Oval and round } \\
\text { Irregular }\end{array}$ & $\begin{array}{l}\text { Benign } \\
\text { Malignant }\end{array}$ & $\begin{array}{l}62 \\
38\end{array}$ & $\begin{array}{l}62 \\
38\end{array}$ \\
\hline \multicolumn{4}{|l|}{ Margin } \\
\hline $\begin{array}{l}\text { Well-circumscribed smooth narrow border } \\
\text { Narrow but jagged border having }<3 \text { lobulations } \\
\text { Ill defined border }\end{array}$ & $\begin{array}{l}\text { Benign } \\
\text { Benign } \\
\text { Malignant }\end{array}$ & $\begin{array}{l}52 \\
10 \\
38\end{array}$ & $\begin{array}{l}52 \\
10 \\
38\end{array}$ \\
\hline \multicolumn{4}{|l|}{ Width/AP ratio } \\
\hline $\begin{array}{l}>1.4 \text { (wider than taller) } \\
<1.4 \text { (taller than wider) }\end{array}$ & $\begin{array}{l}\text { Benign } \\
\text { Malignant }\end{array}$ & $\begin{array}{l}62 \\
38\end{array}$ & $\begin{array}{l}62 \\
38\end{array}$ \\
\hline \multicolumn{4}{|l|}{ Echogenicity } \\
\hline $\begin{array}{l}\text { Anechoic } \\
\text { Hypoechoic } \\
\text { Hyperechoic in relation to fat } \\
\text { More hypoechoic }\end{array}$ & $\begin{array}{l}\text { Benign } \\
\text { Benign } \\
\text { Benign } \\
\text { Malignant }\end{array}$ & $\begin{array}{c}8 \\
14 \\
40 \\
38\end{array}$ & $\begin{array}{c}8 \\
14 \\
40 \\
38\end{array}$ \\
\hline \multicolumn{4}{|l|}{ Internal echoes } \\
\hline $\begin{array}{l}\text { Homogeneous } \\
\text { Intermediate } \\
\text { Heterogeneous }\end{array}$ & $\begin{array}{l}\text { Benign } \\
\text { Benign } \\
\text { Malignant }\end{array}$ & $\begin{array}{l}48 \\
14 \\
38\end{array}$ & $\begin{array}{l}48 \\
14 \\
38\end{array}$ \\
\hline \multicolumn{4}{|l|}{ Edge shadow } \\
\hline $\begin{array}{l}\text { Narrow bilateral } \\
\text { No edge shadow } \\
\text { No edge shadow } \\
\text { Broad unilateral shadow }\end{array}$ & $\begin{array}{l}\text { Benign } \\
\text { Benign } \\
\text { Malignant } \\
\text { Malignant }\end{array}$ & $\begin{array}{c}52 \\
10 \\
30 \\
8\end{array}$ & $\begin{array}{c}52 \\
10 \\
30 \\
8\end{array}$ \\
\hline \multicolumn{4}{|l|}{ Posterior acoustic phenomena } \\
\hline $\begin{array}{l}\text { Enhanced } \\
\text { Attenuated } \\
\text { Unremarkable } \\
\text { Unremarkable }\end{array}$ & $\begin{array}{l}\text { Benign } \\
\text { Malignant } \\
\text { Benign } \\
\text { Malignant }\end{array}$ & $\begin{array}{c}46 \\
34 \\
16 \\
4\end{array}$ & $\begin{array}{c}46 \\
34 \\
16 \\
4\end{array}$ \\
\hline \multicolumn{4}{|l|}{ Pseudocapsule } \\
\hline $\begin{array}{l}\text { Thin echogenic pseudocapsule } \\
\text { Uncapsulated } \\
\text { Thick echogenic halo }\end{array}$ & $\begin{array}{l}\text { Benign } \\
\text { Malignant } \\
\text { Malignant }\end{array}$ & $\begin{array}{c}62 \\
34 \\
4\end{array}$ & $\begin{array}{c}62 \\
34 \\
4\end{array}$ \\
\hline \multicolumn{4}{|l|}{ Compressibility } \\
\hline $\begin{array}{l}\text { Compressible } \\
\text { Less compressible } \\
\text { Noncompressible }\end{array}$ & $\begin{array}{l}\text { Benign } \\
\text { Benign } \\
\text { Malignant }\end{array}$ & $\begin{array}{l}28 \\
34 \\
38\end{array}$ & $\begin{array}{l}28 \\
34 \\
38\end{array}$ \\
\hline \multicolumn{4}{|l|}{ Mobility } \\
\hline $\begin{array}{l}\text { Mobile } \\
\text { Fixed }\end{array}$ & $\begin{array}{l}\text { Benign } \\
\text { Malignant }\end{array}$ & $\begin{array}{l}62 \\
38\end{array}$ & $\begin{array}{l}62 \\
38\end{array}$ \\
\hline \multicolumn{4}{|l|}{ Architectural disruption } \\
\hline $\begin{array}{l}\text { Absent } \\
\text { Present }\end{array}$ & $\begin{array}{l}\text { Benign } \\
\text { Malignant }\end{array}$ & $\begin{array}{l}62 \\
38\end{array}$ & $\begin{array}{l}62 \\
38\end{array}$ \\
\hline
\end{tabular}


On ultrasonography, lesions were diagnosed as benign in $62 \%$ cases and malignant in $38 \%$. Among benign lesions fibroadenoma was found in $44 \%$, breast abscess in $6 \%$, benign cyst in $8 \%$, galactocele in $4 \%$ cases (Table II). Sonographic appearances of carcinoma and fibroadenoma of breast are given in Figures 1 and 2.

Table II: Distribution of the respondents by ultrasonographic diagnoses $(\mathrm{N}=100)$

\begin{tabular}{|l|c|c|}
\hline USG diagnoses & Frequency & Percentage \\
\hline Fibroadenoma & 44 & 44.0 \\
\hline Breast abscess & 6 & 6.0 \\
Benign cyst & 8 & 8.0 \\
Galactocele & 4 & 4.0 \\
\hline Malignant mass & 38 & 38.0 \\
\hline
\end{tabular}

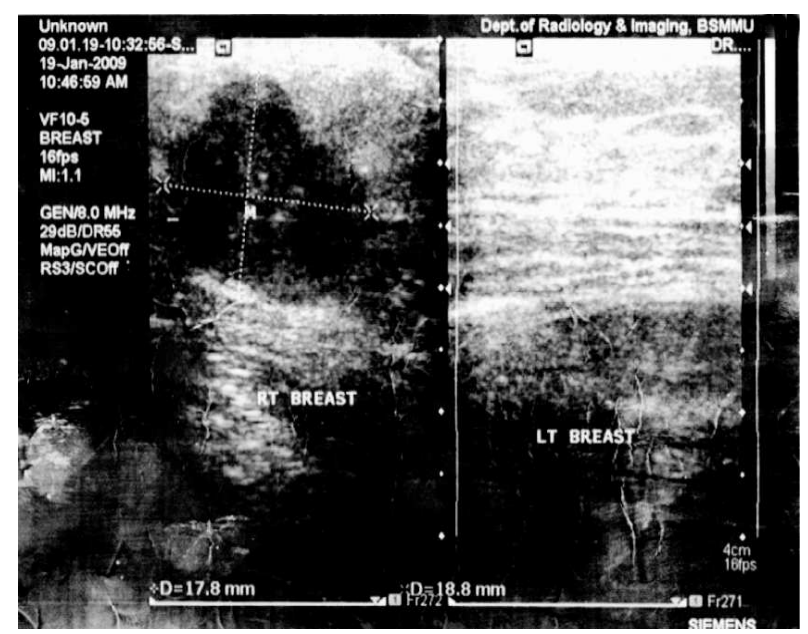

Fig 1. Carcinoma of right breast

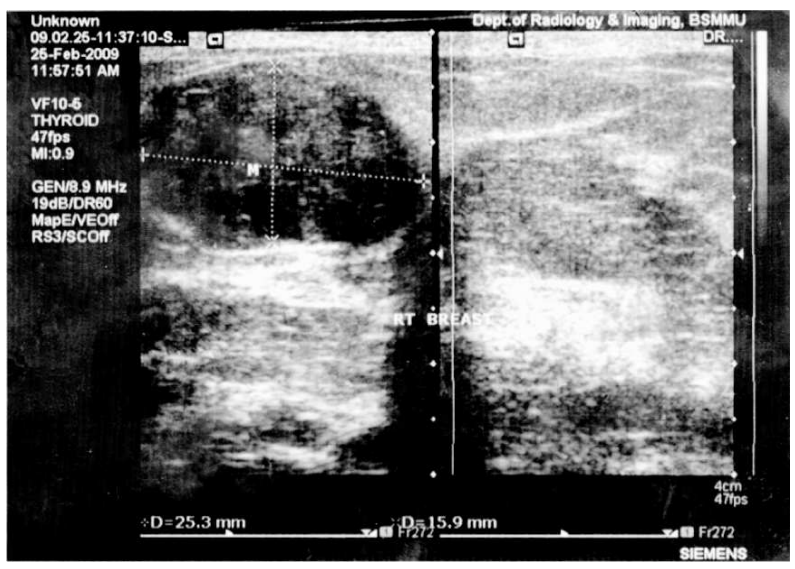

Fig 2. Fibroadenoma of right breast
On histopathology, lesions were diagnosed as benign in $62.0 \%$ cases and malignant in $38.0 \%$. Among benign lesions fibroadenoma was found in $44.0 \%$, breast abscess in $6.0 \%$, benign cyst in $8.0 \%$, galactocele in $4.0 \%$ cases, invasive carcinoma in $34.0 \%$ cases and medullary carcinoma in $4.0 \%$ cases (Table III).

Table III: Distribution of respondents by histopathological findings $(\mathrm{N}=100)$

\begin{tabular}{|l|c|c|}
\hline Histopathological diagnoses & Frequency & Percentage \\
\hline Fibroadenoma & 44 & 44.0 \\
\hline Breast abscess & 6 & 6.0 \\
Benign cyst & 8 & 8.0 \\
Galactocele & 4 & 4.0 \\
\hline Invasive carcinoma & 34 & 34.0 \\
Medullary carcinoma & 4 & 4.0 \\
\hline
\end{tabular}

Sonographically 62 lesions were benign, out of these 58 $(93.5 \%)$ were also proved benign histopathologically, and $4(6.5 \%)$ as malignant. Out of 38 cases who were sonographically diagnosed as malignant, 4 (10.5\%) were diagnosed as benign and $34(89.5 \%)$ were proved that these were malignant (Table IV). In diagnosis of benign lesions by ultrasonogram, sensitivity was $93.5 \%$, specificity $89.5 \%$, positive predictive value (PPV) $93.5 \%$, negative predictive value $89.5 \%$ and accuracy was $92.0 \%$ (Table V). In diagnosis of malignant lesions by USG, sensitivity was $89.5 \%$, specificity $93.5 \%$, PPV $89.5 \%$, NPV $93.5 \%$ and accuracy $92.0 \%$ (Table VI).

Table IV: Distribution of benign and malignant lesions by ultrasonographic and histopathlogical diagnoses $(\mathrm{N}=100)$

\begin{tabular}{|l|c|c|c|}
\hline \multirow{2}{*}{$\begin{array}{l}\text { Ultrasonographic } \\
\text { findings }\end{array}$} & \multicolumn{3}{|c|}{ Histopathological findings } \\
\hline Benign (62) & $58(93.5 \%)$ & $4(6.5 \%)$ & $62(62.0 \%)$ \\
\hline Malignant (38) & $4(10.5 \%)$ & $34(89.5 \%)$ & $38(38.0 \%)$ \\
\hline Total & $62(100.0 \%)$ & $38(100.0 \%)$ & $100(100.0 \%)$
\end{tabular}

Table V: Validity test for ultrasonographic findings for benign lesions $(\mathrm{N}=100)$

\begin{tabular}{|l|c|c|}
\hline & Values & $95 \%$ CI \\
\hline Sensitivity & 93.5 & $87.9-96.7$ \\
\hline Specificity & 89.5 & $80.3-94.6$ \\
\hline PPV & 93.5 & $87.9-96.7$ \\
\hline NPV & 89.5 & $80.3-94.6$ \\
\hline Accuracy & 92.0 & $85.1-95.9$ \\
\hline
\end{tabular}

PPV, Positive predictive value; NPV, Negative predictive value 
Table VI: Validity test for ultrasonographic findings for malignant lesions $(\mathrm{N}=100)$

\begin{tabular}{|l|c|c|}
\hline & Values & $95 \%$ CI \\
\hline Sensitivity & 89.5 & $80.3-94.6$ \\
\hline Specificity & 93.5 & $87.9-96.7$ \\
\hline PPV & 89.5 & $80.3-94.6$ \\
\hline NPV & 93.5 & $87.9-96.7$ \\
\hline Accuracy & 92.0 & $85.1-95.9$ \\
\hline
\end{tabular}

PPV, Positive predictive value; NPV, Negative predictive value

\section{Discussion}

Despite advancement and multifold improvement in scientific knowledge, at present there is no known method for primary prevention of breast cancer. Under the present circumstances, early detection and treatment of breast cancer as a secondary preventive measure seems to be the most appropriate approach for reducing mortality due to breast cancer and for improving quality of life. Breast imaging is most routinely used for screening and diagnostic tool to detect and manage breast cancer. Benign breast lesions are vastly more common than malignant lesions and often require accurate diagnosis to rule out cancer and determine the best treatment and for this at first a breast lump should be differentiated as either benign or malignant.

The current study was performed to explore the sonographic discrimination of benign and malignant breast lumps with histopathological correlation. One hundred women who attended department of Radiology \& Imaging, BSMMU with breast lumps were enrolled in the study. USG and histopathology were done and correlated.

Rahbar et $\mathrm{al}^{11}$ found that the features most likely to predict a benign diagnosis in solid masses were round or oval shape, had a circumscribed margin, and had a width-to-anteroposterior ratio greater than 1.4. Denis et $\mathrm{al}^{12}$ also found that the characteristic sonographic findings of benign tumors include a round or oval, slightly hypoechoic lesion with smooth borders or a pseudocapsule, homogeneous internal echoes, no central posterior acoustic shadowing, and normal surrounding tissue. In our study the ultrasonographic features most predictive of a benign diagnosis were oval and round shaped in $62 \%$ cases, well circumscribed smooth narrow margin in $52 \%$ cases and width/AP ratio $>1.4$ in $62 \%$ cases, thin echogenic pseudocapsule was seen in $62 \%$ cases, posterior acoustic enhnacement in $46 \%$ cases, $28 \%$ cases were compressible and $34 \%$ cases were less compressible, $62 \%$ cases were mobile and showed no architectural disruption, $40 \%$ cases were hyperechoic in relation to fat, anechoic in $8 \%$ cases and hypoechoic in $14 \%$ cases, $48 \%$ cases were homogeneous in echotexture.

Rahbar et al ${ }^{11}$ also found that features most predictive of malignancy were irregular shape, microlobulated or spiculated margin, and width-to-anteroposterior ratio of less than or equal to 1.4. These results were also in conformity to the results obtained by Kailash et al. ${ }^{13}$ The typical features of malignancy include irregular shape, irregular contour, hypoechogenicity, a surrounding echogenic rim due to compression and distortion of the surrounding tissue, and posterior acoustic shadowing. ${ }^{14,15}$ In our study, sonographically most predictive malignant features were irregular shape with ill defined margin in $38 \%$ cases, width/AP ratio $<1.4$ in $38 \%$ cases, $38 \%$ cases were heterogeneously more hypoechoic, broad unilateral edge shadow were seen in $8 \%$ cases and no edge shadow was found in $30 \%$ cases, posterior acoustic attenuation was in $34 \%$ cases, $34 \%$ cases were uncapsulated and $4 \%$ cases having thick echogenic halo, 38\% cases were noncompressible, fixed and showed architectural disruption.

According to Pande et $\mathrm{al}^{16}$ shape, margins, vascularity, surrounding tissue character, sound transmission through the lump are more significant in the diagnosis of benign vs malignant lumps. Echogenicity and echotexture are less significant. ${ }^{16}$ Mass margin is a critical feature for determining whether a lesion is benign or malignant according to Stavros et $\mathrm{al}^{14}$. A brightly reflected zone corresponding to posterior margin of the tumor may suggest the presence of a fibroadenoma rather than carcinoma where posterior shadowing is present. ${ }^{17}$ Edge or lateral shadowing, considered to be a characteristic of benign tumor, has also been reported in some malignant tumors and was recorded in $10 \%$ of carcinomas in one series. ${ }^{18}$

In a study by Zhi et al ${ }^{19}$ of 296 lesions, 87 were histologically malignant, and 209 were benign. In our study, sonographically 62 lesions were benign; out of these $58(93.5 \%)$ were also proved benign histopathologically, and 4 (6.5\%) malignant. Out of 38 cases, which were sonographically diagnosed as malignant, $4(10.5 \%)$ were diagnosed as benign and 34 $(89.5 \%)$ were proved malignant. 
The study by Pande et al $^{16}$ had a sensitivity value of $95 \%$, specificity of $94.10 \%$, positive and negative predictive values of $95.50 \%$ and $93.75 \%$. Zhi et al ${ }^{19}$ found that sonography (B-mode) revealed sensitivity of $71.2 \%$, specificity $73.2 \%$, accuracy $72.6 \%$, PPV $52.5 \%$ and NPV $86.0 \%$. In our study, in diagnosis of benign lesions by ultrasonogram, sensitivity was $93.5 \%$, specificity $89.5 \%$, PPV $93.5 \%$, NPV $89.5 \%$ and accuracy $92.0 \%$. In diagnosis of malignant lesions by ultrasonogram, sensitivity was $89.5 \%$, specificity 93.5\%, PPV 89.5\%, NPV 93.5\% and accuracy $92.0 \%$.

In our study although there is an overlap between the sonographic appearances of benign and malignant lesions, we found significant sensitivity, specificity, accuracy, positive predictive value and negative predictive value in the diagnosis of both benign and malignant breast lumps. So, we can conclude that ultrasonography is a sensitive imaging tool to differentiate benign and malignant breast lumps. Therefore, ultrasonography can be used as an initial investigation that may guide other subsequent investigations.

\section{References}

1. Goehring C, Morabia A. Epidemiology of benign breast disease, with special attention to histologic types. Epidemiol Rev 1997; 19(2): 310-327.

2. Hakinson S, Hunter D. Breast cancer. In: Adam HO, Hunter D, Trichopoulos D (eds). Textbook of cancer epidemiology. New York, NY: Oxford University Press, 2002: 301-339.

3. Tabar L, Yen MF, Vitak B, Chen HH, Smith RA, Duffy SW. Mammography service screening and mortality in breast cancer patients: 20-year follow-up before and after introduction of screening, Lancet 2003; 361: 1405-1410.

4. Donegan WL. Evaluation of a palpable breast mass. N Engl J Med 1992; 327: 937-942.

5. Huynh PT, Jarolimek AM, Daye S. The false-negative mammogram. Radiographics 1998; 18: 1137-1154.

6. Duncan JL III, Cederbom GJ, Champaign JL. Benign diagnosis by image-guided core-needle breast biopsy. Am Surg 2000; 66: 5-10.
7. Sickles E, Filly R, Callen P. Breast cancer detection with sonography and mammography: comparison using state-ofthe-art equipment. Am J Roentgenol 1983; 140: 843-845.

8. Kopans D, Meyer J, Lindfors K. Whole-breast US imaging: four-year follow-up. Radiology 1985; 157: 505.

9. Ciatto S, Del Turco MR, Catarzi S. The contribution of ultrasonography to the differential diagnosis of breast cancer. Neoplasma 1994; 41(6); 341-345.

10.Lister D, Evans A, Burrell H. The accuracy of breast ultrasound in the evaluation of clinically benign discrete, symptomatic breast lumps. Clin Radiol 1998; 53: 490-492.

11. Rahbar G, Sie AC, Hansen GC. Benign versus malignant solid breast masses: US differentiation. Radiology 1999; 213: 889-894. [PubMed]

12. Dennis MA, Parker SH, Klaus AJ, Stavros AT, Kaske TI. Breast biopsy; the value of normal mammograms and normal sonograms in the setting of a palpable lump. Radiology 2001; 219: 186-191.

13. Kailash S, Tariuq A, Ghanshyam DG, The accuracy of ultrasound in diagnosis of palpable breast lumps. Journal of Medical Education \& Research 2008; 10(4): 186-188.

14. Stavros AT, Thickman D, Rapp CL. Solid breast nodules: use of sonography to distinguish between benign and malignant lesions. Radiology 1995; 196: 123-134.

15. Vlaisavljevic V. Differentiation of solid breast tumours on the basis of their primary echographic characteristics as revealed by real time scanning of the uncompressed breast. Ultrasound Med Biol 1988; 14(Suppl 1): 75-80.

16. Pande AR, Lohani B, Sayami P, Pradhan S. Predictive value of ultrasonography in the diagnosis of palpable breast lump. Kathmandu Univ Med J 2003; 1(2): 78-84.

17. Guyer PB, Dewbury KC, Warwick D, Smallwood J, Taylor I. Direct contact B scan ultrasound in the diagnosis of solid breast masses. Clin Radiol 1986; 37: 451-458.

18. Harper AP, Kelly-Fry E, Noe JS, Bies JR, Jackson VP. Ultrasound in the evaluation of solid breast masses. Radiology 1983; 146: 731-736.

19. Zhi H, Ou B, Luo B, Feng X, Wen Y, Yang H. Ultrasound elastography in solid breast lesions. J Ultrasound Med 2007; 26: 807-815. 